\title{
Nietzsche e o controverso ideal de emancipação feminina
}

\author{
Patrícia Sheyla Bagot de Almeida
}

\begin{abstract}
Resumo: Se as considerações de Nietzsche sobre a mulher são variadas, difíceis e até problemáticas, posto que não se pode atribuir um único sentido ao termo, o mesmo, em parte, não ocorre com o termo emancipação. Nietzsche apresenta aforismos nos quais demonstra algumas noções atribuídas ao termo. Não obstante, o filósofo trata da emancipação feminina não do ponto de vista exclusivamente político, mas da mulher como uma ideia "em si". Neste artigo, partirei de alguns aforismos da obra Além do bem e do mal, de 1886, na qual é possível verificar o sentido que ele dá ao termo, assim como esquadrinhar os indícios do modo como ele lê a crença da igualdade buscada pela mulher, a fim de demonstrar a incoerência da proposta de emancipação, uma vez que, a partir da quebra da distinção e do abandono da diferença entre homem e mulher, é que se exigia o sacrifício da internalização dos valores masculinos em um consequente esvaziamento, embotamento e regressão do que é singular na mulher. Para desenvolver o objetivo proposto, relacionarei o tema a outros aforismos a fim de ressaltar que a problemática da emancipação feminina como condição sine qua non de pertencimento do espaço público, locus no qual as ações políticas são efetivas e consideradas, fora também problematizadas por Wollstonecraft, no que Carole Pateman denominou o "dilema Wollstonecraft", a saber, exigir igualdade é aceitar a concepção patriarcal de cidadania, na qual as mulheres devem parecer-se aos homens a fim de serem vistas no cenário público, âmbito da ação política. Assim, buscarei examinar a análise de Nietzsche no que tange a emancipação feminina e seus desdobramentos conceituais, sem, no entanto, deixar de realizar outras tecituras com autoras que pensaram essa concepção.
\end{abstract}

Palavras-chave: Emancipação - Mulher - Igualdade - Educação - Singularidade

\section{Nietzsche and the controversial ideal of female emancipation}

\begin{abstract}
If Nietzsche's considerations about women are varied, difficult and even problematic, since a single meaning cannot be attributed to the term, the same, in part, does not occur with the term emancipation. Nietzsche presents aphorisms in which he demonstrates some notions attributed to the term. Nevertheless, the philosopher deals with female emancipation not from an exclusively political point of view, but from women as an idea 'in itself'. In this article, I will start with some aphorisms of the work Beyond good and evil, 1886, in which it is possible to verify the meaning he gives to the term, as well as to examine the evidence in the way he reads the equality belief sought by women, in order to demonstrate the inconsistency of the emancipation proposal, since, from the breaking of the distinction and the abandonment of the difference between man and woman, it was necessary to sacrifice the internalization of male values in a consequent emptying, dullness and regression of what it is unique in women. To develop the proposed objective, I will relate the theme to other aphorisms, in order to emphasize that the issue of female emancipation as a sine qua non condition of belonging to the public space, locus in which political actions are effective and considered, had also been problematized by Wollstonecraft, in what Carole Pateman called the "Wollstonecraft dilemma", namely, to demand equality is to accept the patriarchal conception of citizenship, in which women must resemble men in order to be seen on the public scene, within the scope of political action. Thus, I will seek to examine Nietzsche's analysis with regard to female emancipation and its conceptual developments, without, however, failing to make other weavings with authors who thought this conception.
\end{abstract}

Keywords: Emancipation - Woman - Equality - Education - Singularity

${ }^{1}$ Mestranda pelo Programa de Pós-Graduação em Filosofia da Universidade Federal de Goiás (UFG). E-mail: Sheylaba7@hotmail.com 


\title{
Considerações iniciais
}

\author{
Abaixo da cintura são centauros, \\ Muito embora mulheres para cima. \\ Até a cintura os deuses é que mandam; para baixo, os demônios. \\ Ali é o interno, escuridão, abismo sulfuroso, calor, fervura, cheiro de podridão! \\ Shakespeare, Rei Lear, 1606.
}

Já se faz tarde problematizar o que os filósofos falaram ou silenciaram sobre "a mulher", em categorias, como se elas fossem naturalmente universais, inclusivas e totais. No repensar de tais categorias, Nietzsche figura entre os pensadores que elaboraram deslocamentos. E se a filosofia dele, no que respeita à abordagem sobre a mulher, é difícil e até contraditória, dados os inúmeros aforismos em que ele reflete falas e posicionamentos femininos, também é difícil manter uma única possibilidade de leitura sobre esse assunto. São inúmeros aforismos em que observamos a expressão "mulher", muitos utilizando metáforas como recurso para torção sobre outros conceitos, numa elaboração simbólica e experimental. Outros, diretos na colocação ou irônicos na exposição, e outros refletindo o modo jocoso com que a época associava a expressão "mulher" a epítetos de fraqueza que o próprio Nietzsche desconstrói.

No entanto, talvez o que torne a questão mais complexa é que nenhum aforismo pode ser lido como acabado, completo e final. Ao contrário das filosofias sistemáticas de escrita linear, a escolha pelo aforismo é uma escolha pela subversão da regra da inteligibilidade, e também uma estratégia de performance com a recepção. Nas observações do estudioso Rogério Lopes, enquanto a "filosofia sistemática valoriza a fundamentação e o acabamento. O ensaio aforismático em Nietzsche valoriza a abertura, a pluralidade de perspectivas e a possibilidade de que a interpretação seja uma tarefa infinita" ${ }^{2}$, haja vista que a fundamentação é impossível e, para Nietzsche, nem sequer desejável.

Outro fator que dificulta a leitura dos aforismos de Nietzsche é o tempo em que o filósofo os escreve, época em que o feminismo ainda lançava suas primeiras bases enquanto movimento propriamente dito. Embora os movimentos e as contestações de mulheres tenham construído uma trajetória de diferentes aspectos e matizes no decorrer da história, foram os acontecimentos do século XVIII, aliados à Revolução Francesa, em que circulavam, por exemplo, as ideias de Mary Wollstonecraft (1759 - 1797) e sua contemporânea Olympe de Gouges (1743 - 1794), destacadas por um feminismo na idade das luzes, que atribuíram um aspecto político à causa.

Nesta época, na qual se desenvolvia a crença no conhecimento da verdade proveniente da razão e da ciência, não podemos pensar a mulher descolando-a dos temas que estavam na ordem do exercício de sua compreensão: igualdade, liberdade e fraternidade. Neste conjunto de ideias que circulavam na Europa em torno da igualdade de direitos, vemos Nietzsche, por meio de sua filosofia, no trato de tais questões, num exercício de delineamento dos valores morais nos quais se assentavam as crenças libertárias que povoaram a época da Revolução.

\footnotetext{
${ }^{2}$ LOPES, "Entre ensaio e aforismo: notas sobre o modo de apresentação dos argumentos na filosofia de
} Nietzsche", p. 283. 
Dito isto, pretendemos explicitar por que falar de emancipação, para Nietzsche, é duvidoso, e demonstrar como tal conceito foi interpretado e assumido pelas mulheres. Sendo assim, apresentaremos os seguintes pontos: primeiro, analisaremos o contexto em que a emancipação se tornou uma palavra importante para os movimentos revolucionários na Europa, dando destaque à Revolução Francesa, que marcou o sonho pela emancipação. Segundo, demonstraremos como Nietzsche leu este movimento, buscando junto a esta marcação o que o filósofo elabora sobre a ideia de mulher. E, por último, tentaremos apresentar as controvérsias do desejo de emancipação feminina que, segundo o filósofo, significou, entre outras coisas, a perda e o embotamento da mulher.

Para ampliar nossa interpretação da abordagem de Nietzsche sobre a revolução e a emancipação dela provinda, utilizaremos, para além da argumentação do filósofo, um exemplo de como as ideias emancipadoras foram vivenciadas e compreendidas por Mary Wollstonecraft, que embora fosse anterior a Nietzsche, foi relida por feministas posteriores na chave da emancipação e dos direitos da mulher. A fim de alcançar esta tarefa, dividiremos este artigo em dois subtópicos. No primeiro, demonstraremos alguns ideais da Revolução Francesa e a consequência da crença em seus valores; e, no segundo, demonstraremos como o conceito de emancipação serviu, em parte, para, segundo a leitura nietzschiana, o embotamento da mulher no cenário em que se fez crer que esta seria a única forma possível de mudar as condições de representação da mulher.

\section{Os ideais da Revolução Francesa e a debilitação do indivíduo}

Nietzsche compreende a Revolução Francesa pelo seu substancial ideário. Em diversos aforismos de Para além do bem e do mal (1992) e outras obras, o filósofo considera a Revolução como disseminadora das ideias do esclarecimento, cuja constituição pautava-se nos valores modernos da crença na razão. A Revolução, portanto, seria o cume de difusão dos valores modernos, do iluminismo, e de um tipo de moral na qual tais valores se sedimentavam, a saber, a moral cristã. Disto resulta que os valores mais propalados da Revolução sejam a crença de justiça, de igualdade e de fraternidade. No entanto, se este era o real motivo e emblema da Revolução, por que Nietzsche se mostra, em alguns aforismos, desconfiado e crítico desses valores?

Em Para além do bem e do mal, de 1886, o filósofo aborda diretamente a Revolução, acusando-a de ser "uma farsa horrível e desnecessária", mas é, sobretudo, no aforismo 46 de "A natureza religiosa" que encontramos a explícita desconfiança de Nietzsche quanto à Revolução, isto é, sua origem, ou mais precisamente, a origem de seus valores que, para o filósofo, é cristã.

Desta forma, para compreendermos a relação que o filósofo estabelece entre Revolução e cristianismo é necessário acompanhar a investigação genealógica entre os valores morais do mundo antigo e do mundo cristão, ou seja, o cristianismo original em contraposição a um tipo de valor moral de livre pensar no mundo meridional cético. Os valores cristãos têm na fé um modo de sacrifício, no qual se sujeita "toda liberdade, todo orgulho, toda confiança do espírito em si mesmo; e ao mesmo tempo solidão e autoescarnecimento, automutilação". Esse modo de fé constitui-se numa “consciência debilitada,

${ }^{3}$ NIETZSCHE, Para além de bem e mal, JGB/BM, \$38, p. 43. 
múltipla e de muitos vícios e seu pressuposto é que a submissão do espírito seja indescritivelmente dolorosa"4.

Essa expressão do sacrifício de si e submissão do espírito pela dor representa uma inversão em relação aos valores do mundo meridional, dos gregos. Trata-se, no plano moral, de desconstruir outros modos de valorar a vida que não assentavam sua existência sobre o martírio e renúncia do indivíduo. A inversão de valores que se realizou pelo instinto de conservação, isto é, mais pela sobrevivência do que pela vida, obliterou a percepção do homem moderno. É com base no esquema genealógico da moral que o filósofo considera que a inversão dos valores que afirmam a vida por aqueles que a negam, teve na Revolução Francesa sua grande última rebelião. Por tal razão, Nietzsche esforça-se em investigar como a "ilustração" estava sobre a égide da moral cristã, e como a Revolução Francesa foi aquela "que colocou o cetro, solenemente e sem reservas, nas mãos do 'homem bom' (do cordeiro,

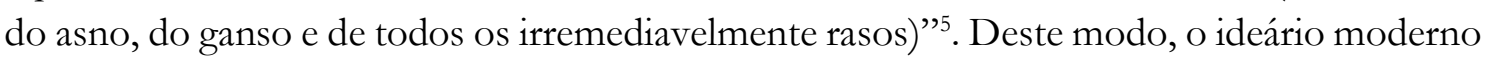
e ilustrado da Revolução nada mais fez do que alastrar a inversão da moral cristã. Alastrar no sentido de popularização desses ideais, que tinham como efeito o enfraquecimento e a supressão do indivíduo ${ }^{6}$, ou seja, torná-lo gregário a partir do apagamento de si próprio e do embotamento da vida.

Citando vários ecos do ideário da moral do sacrifício, Nietzsche afirma que "essas doutrinas brotaram com ímpeto poderoso em toda parte, simultaneamente nas mais finas e mais grosseiras formas, aproximadamente a partir da época da Revolução Francesa" ". E a consequência da extensão de tais pressupostos morais levou os indivíduos a se adequar às necessidades, cujo sacrifício de si reduziu-se a sentir-se um membro útil à comunidade. Portanto, a problemática aqui exposta é a redução do indivíduo a um todo abstrato pertencente à moral efetiva de uma comunidade, na qual "o homem medíocre procura instituir maneiras de agir e pensar universalmente válidas, censurar toda originalidade, reprovar qualquer mudança" ". Assim sendo, o todo requer a adequação e remodelação dos indivíduos em membros, ação realizada por "uma administração mais econômica, mais segura, mais equilibrada, mais uniforme"".

Neste modo de existência dos membros moralmente fundamentados se conjugam a moralidade uniforme e a concepção de igualdade. Dito de outro modo, esta junção, cuja ideia iguala a todos, além de ter sido fortemente difundida pela Revolução, tem como um de seus princípios a igualdade que, no que concerne à manutenção da vida, é apenas um nivelamento gregário herdado dos valores cristãos. Um modo de sobrevivência que inventa a igualdade como equilíbrio das forças entre os diferentes, nos quais fortes e fracos têm suas diferenças supostamente suprimidas e amenizadas.

Trata-se mesmo da necessidade de manter sobrevivente e de produzir uma força coletiva a fim da conservação da vida. A garantia está no fato de que vivendo gregariamente, os sujeitos tornam-se mais fortes para enfrentar possíveis ameaças, assim como, caso "os adversários - fossem indivíduos ou grupos - sempre que tivessem forças equivalentes,

\footnotetext{
${ }^{4}$ NIETZSCHE, Para além de bem e mal, JGB/BM, \$46, p. 52.

${ }^{5}$ NIETZSCHE, A Gaia Ciència, FW/GC, \$350, p. 244.

${ }^{6}$ NIETZSCHE, Aurora, MO/A, \$132, pp. 94-95.

${ }^{7}$ NIETZSCHE, Aurora, MO/A, \$132, p. 95.

${ }^{8}$ MARTON, "Nietzsche e a crítica da democracia", p. 21.

${ }^{9}$ NIETZSCHE, Aurora, MO/A, \$132, p. 96.
} 
concluíam a paz e estabeleciam contrato entre si" ${ }^{10}$. Neste sentido, a igualdade é, contraditoriamente à sua crença ideal, um artifício astuto de manutenção do privilégio daqueles que podem dizer o que se deve acordar na vida gregária e o que se deve repudiar.

Atida à necessidade e à fixação de um conceito, a igualdade se torna uma doença e não possui sustentação na dinâmica da vida. Por esta razão, Nietzsche cria um problema ao perguntar sobre a possibilidade da manutenção de uma forma de política que abra mão da vida em sua portentosa diversidade vivencial e do seu perspectivismo de afecções. Neste sentido, ele, assegurado por pensar a vida, negação da definição conceitual única, critica a forma como essa ideia se mantém, pois mesmo que a vida humana seja elaborada em grupo, o engodo parece ser que, na trajetória do espírito humano, nunca houve iguais. Seja por consenso ou contrato, partimos de pressuposições hipotéticas e nos fixamos nela (igualdade) como evento da verdade absoluta, ou seja, a modernidade, que disseminou a crença na razão, fez acelerar o ser teórico que leva ao aprofundamento da naturalização daquilo que é estranho à própria vida. Para maior efetivação da igualdade, é preciso aderir a um modelo de educação presa à ficção da igualdade, não porque de fato possa ser ou deseje ser igual, mas porque é a boa avaliação e adequação ao padrão assentido como bom que parece assegurar o usufruto dos "bens" da sociedade para alguns. Dito de outro modo, é a aceitação do todo que facilita o enquadramento do que é diverso, diferente, estranho à sociedade.

Nestes valores, a educação é uma abnegação, pois importam os efeitos que as virtudes ensinadas têm para a sociedade, sempre seguindo uma ordem em que os indivíduos devem atuar, afinal "as virtudes de um homem não são chamadas de boas em vista dos efeitos que tenham para ele, mas em vista dos efeitos que pressupomos que tenham para nós e a sociedade"11. À vista disso, tendo êxito a educação, cada virtude do indivíduo torna-se uma utilidade pública e uma desvantagem particular. Os valores de uma educação racional, na qual está posta o desejo de emancipação, são a base da educação moral e, neste sentido, "a moralidade não é outra coisa (e, portanto, não mais!) do que obediência a costumes, não importa quais sejam; mas costumes são a maneira tradicional de agir e avaliar" ${ }^{\prime 2}$. Logo, podemos compreender em que sentido o filósofo hesita diante dos valores emancipatórios, tais como igualdade, liberdade e fraternidade. E é nesta chave que buscamos criar hipóteses para elucidar os motivos de Nietzsche ter se referido ao desejo de emancipação, de independência das mulheres, como "um dos piores progressos de enfeamento geral da Europa"13.

\section{A emancipação como embotamento da mulher}

Sobre a emancipação da mulher, Nietzsche elabora a seguinte questão: "podem as mulheres ser justas, se estão tão acostumadas a amar, a imediatamente simpatizar ou antipatizar? Em virtude disso não têm tanto interesse por causas como têm por pessoas" ${ }^{14}$. $\mathrm{Na}$ primeira sentença do aforismo, a palavra "acostumadas" parece relacionar-se com um tipo de educação oriunda do que a tradição considerou importante para as mulheres: o amor,

\footnotetext{
${ }^{10}$ MARTON, "Nietzsche e a crítica da democracia", p. 22.

${ }^{11}$ NIETZSCHE, A Gaia Ciência, FW/GC \$21, p. 69.

12 NIETZSCHE, Aurora, MO/A, §9, p. 17.

${ }^{13}$ NIETZSCHE, Para além de bem e mal, JGB/BM, \$232, p. 139.

${ }^{14}$ NIETZSCHE, Humano, Demasiado Humano, MA/HH I, $\$ 416$.
} 
significado para docilidade, paixão e cuidado voltado para a oscilação e as afetações dos humores. Em virtude desta educação, as mulheres se ligariam mais às pessoas do que a causas ou engajamentos, sejam eles políticos, sociais ou científicos. Entretanto, quando as mulheres se voltam para essas causas de engajamento, acabam por seguir o mesmo caminho dos homens em seus valores modernos, a saber, deixam-se guiar pela política e pela ciência. A primeira se relacionaria à igualdade entre os homens, no sentido de torná-los servis e úteis para as instituições, desenvolvendo o modo igualitário de rebanho; e a segunda, estaria na eleição de um único conhecimento verdadeiro e na crença do progresso cientificista do homem. Todavia, na pretensão de enquadramento moral em torno de um único modo de existência tida como boa, verdadeira e certa, a vida dinâmica, em sua potencialidade criativa, é diminuída e enfraquecida, uma vez que vida, no sentido nietzschiano, diz respeito à "luta constante entre impulsos para o aumento da potência; nessa luta, para crescer, um impulso deve dominar os outros", e o "crescimento de potência e exercício de dominação são condições para a auto-superação, ou seja, para um processo dinâmico e contínuo de incremento de força ou impulso" $"$.

Envolto a essas considerações de incremento de força, destacamos, segundo Nietzsche, o quanto ainda permaneceria na mulher um quantum de vida criativa, dado seu desprezo pelo enquadramento e adestramento da vida. Ao dizer sobre o desprezo que a mulher mantém frente às "crenças dos conhecimentos" de enfraquecimento da vida, está a dizer também que a abundância de vida é superior a qualquer conhecimento que tente sufocála. Deste modo, nos termos elaborados por Nietzsche nos aforismos em que ele trata sobre a mulher, emancipar-se nada mais é do que escolher o lugar comum de castração do próprio indivíduo.

Isto exposto, seguimos a orientação de Juan Maresca, segundo o qual nos "parágrafos 231-239 de Para além do bem e do mal que se apresentam uma das expressões mais acabadas contra a emancipação feminina"16. Nestes aforismos, Nietzsche apresenta a ideia de "mulher em si”, da emancipação e da razão, do antagonismo entre homem e mulher, feminismo, Revolução Francesa, entre outros. Embora não seja objetivo deste artigo trabalhar todos os aforismos em questão, analisaremos o aforismo 232, importante para a compreensão da ideia de "mulher em si", marcada por aspas com a finalidade de evidenciar que se trata de uma ideia aos moldes de uma filosofia dogmática de verve platônica, como ficará explícito mais a frente neste estudo.

O aforismo trata da ideia de "mulher em si" ou de mulher científica, um dentre outros tipos que o filósofo elabora a fim de expor sua filosofia. Nele, diz Nietzsche: "a mulher quer ser independente: e com tal objetivo começa a esclarecer os homens sobre a 'mulher em si' - este é um dos piores progressos de enfeamento geral da Europa" ${ }^{17}$. Numa primeira leitura, poderíamos estranhar o emprego da palavra "enfeamento", todavia, com base na análise dos valores morais que sedimentam os acontecimentos da Revolução, já apresentada na primeira parte deste artigo, fica evidente que falar de si é recorrer ao modo científico, racional, de objetificar a vida. Nesta lógica, a ideia de "mulher em si", refere-se diretamente à crença da mulher científica, uma vez que esta passa a crer que há uma verdade acerca de si a ser

\footnotetext{
${ }^{15}$ FREZZATTI, “A superação da dualidade cultura/biologia na filosofia de Nietzsche”, p. 118.

${ }^{16}$ MARESCA, “A emancipação da mulher", p. 108.

${ }^{17}$ NIETZSCHE, Para além de bem e mal, JGB/BM, \$232, p. 139.
} 
comunicada. A partir desta concepção, Nietzsche questiona: "não é de péssimo gosto que a mulher se disponha de tal modo a ser científica?”"18.

Atentemos para o peso da tradição que os termos elencados por Nietzsche - ciência, verdade, esclarecimento - possuem. Conceitos impregnados da inversão moral que passou, segundo o filósofo, despercebida pelos modernos e que foi exponenciada pelo iluminismo e pela Revolução. A moral única, que desencadeia o enfraquecimento da vida como criação, demonstra que estes termos só podem colocar-se pelo distanciamento do indivíduo de si mesmo. Logo, as mulheres buscam prender-se na manutenção de um modelo moral de tipo gregário. Por tal razão, Giacóia Jr. ${ }^{19}$ considera a ideia de "mulher em si" uma reedição da estratégia de idealização da moral. Ou seja, o que está posto é a promoção de um tipo de categoria de mulher enquadrada pelo ideário aos moldes masculinos, uma vez que a própria mulher, caso de desprezo pela tradição moral judaico-cristã, observa a necessidade de se construir dentro de um ideal compartilhável e igualitário, ou seja, uma ideia de "mulher em si" cujos atributos ideativos sejam aceitáveis.

$\mathrm{Na}$ busca de emancipação, a mulher precisa primeiramente falar de si na adesão ao ideal moderno, lançar mão de um discurso e, para isto, recorre à objetificação do que é, categorizando-se a si mesma. É neste sentido que Nietzsche considera que ao elevarem "a si mesmas como 'mulher em si', como 'mulher superior', como 'idealista feminista', querem rebaixar a posição geral da mulher" ${ }^{20}$. Prerrogativa somente alcançada através do apagamento do valor da vida e, no caso da mulher, do apagamento de si mesma em prol da repetição dos valores morais já postos.

Da apreciação filosófica à apreciação histórica, valemo-nos agora, a fim de dar ênfase à análise de Nietzsche, de um exemplo de como as ideias que circulavam sobre a emancipação da mulher eram embasadas nos ideários da razão masculina do XVIII. Nas prerrogativas de Wollstonecraft, em sua obra Reivindicação dos direitos da mulher, publicado em 1792, em resposta à Constituição Francesa de 1791, encontramos um honesto questionamento sobre a condição e, principalmente, a educação da mulher que inclui o cultivo das virtudes masculinas, os quais, segundo a autora, suscitam grande resistência às "mulheres masculinas". Quanto a esta resistência, diz Wollstonecraft:

Mas, se forem contra a imitação das virtudes masculinas ou, dito de modo mais adequado, contra a obtenção desses talentos e virtudes, cujo exercício enobrece o caráter humano e eleva as fêmeas na escala de seres animais, ao serem incluídas nos termos mais abrangentes da humanidade, devo pensar que todos aqueles que as observam com um olhar filosófico têm de desejar, ao meu lado, que elas se tornem cada dia mais e mais masculinas ${ }^{21}$.

Ter que desejar mais e mais as virtudes masculinas e uma educação formal, cuja essência seja a faculdade da razão, são a garantia de reconhecimento e valoração na sociedade. Em nome do cultivo da razão, Wollstonecraft afirma: "presumo que os homens racionais desculpar-me-ão por me esforçar em persuadi-las a se tornar mais masculinas e

\footnotetext{
${ }^{18}$ NIETZSCHE, Para além de bem e mal, JGB/BM, \$232, p. 140.

${ }^{19}$ GIACÓIA, "Nietzsche e o feminismo", p. 15.

${ }^{20}$ NIETZSCHE, Ecce Homo, EH, \$5, pp. 56-57.

${ }^{21}$ WOLLSTONECRAFT, Reivindicação dos Direitos das Mulheres, p. 26.
} 
respeitáveis"22. Ratificamos que a obra de Wollstonecraft se inscreve em um cenário político de questões sociais que questiona a exclusão da mulher da esfera pública e, consequentemente, seu confinamento no espaço privado. Todavia, sua obra reflete a crença na verdade da razão e atribui à ausência do cultivo desta a exclusão das mulheres dos direitos sociais.

Esta postura intelectual, tomada pelo atributo masculino de que as mulheres devem imitar a fim de alcançar a cidadania plena, denominada "dilema Wollstonecraft" 23 por Carole Pateman, indica que se o feminismo avançou ao traçar as visibilidades da opressão, "ele mal começou a reconhecer o problema da colocação de mulheres em uma ordem política na qual a cidadania foi criada à imagem e semelhança do homem" ${ }^{24}$. Eis porque a solicitação de direitos iguais torna-se impraticável. Primeiro, porque para que a mulher adquira o status de cidadã deve se tornar um homem e, segundo, porque "embora a mulher tenha exigido por dois séculos que suas tarefas e qualidades distintivas fizessem parte da cidadania da mulher", estas atividades sempre a colocavam em sentido oposto ao da cidadania. $\mathrm{O}$ almejado mesmo, segundo Pateman, era que ou "a mulher vista a pele do leão com crina e tudo, ou se espere que entre em seu lugar entre os novos homens postulados na teoria democrática radical e não se distinga deles" 25 . O que equivale a dizer que as únicas qualidades possíveis para que uma mulher adquira direitos é que ela se torne um homem, ou continue restrita às suas atividades femininas. Eis o dilema: buscar igualar-se ao que as violenta, discrimina e silencia.

Direito político e igualdade na esfera pública como sonhara Wollstonecraft são, segundo Pateman, exigências incompatíveis, porque não permitem nenhuma transformação radical, porque solapam as diferenças de gêneros e porque subordinam ainda mais as mulheres aos homens. Ou seja, para Pateman, buscar direitos tais como a igualdade política ainda é manter-se em um território dos direitos masculinos, porque pensados por eles na ótica de suas próprias necessidades, nas condições deles.

Não se trata, neste ponto, de abrir mão dos direitos sociais que foram arduamente conquistados durante o processo histórico, mas de agora perquirir aqueles que ficaram de fora ou aqueles que simplesmente não contaram para estes direitos, sejam os escravos, as mulheres, as crianças, os trabalhadores, entre outros que estavam restritos a um mundo privado ou de mera reprodução do trabalho doméstico. Ressalta ainda Pateman ${ }^{26}$, que as mulheres não participaram de nenhum dos direitos que foram acertados no cenário político das relações sociais. Neste sentido, as mulheres foram apenas objeto dos direitos civis e não

\footnotetext{
${ }^{22}$ WOLLSTONECRAFT, Reivindicação dos Direitos das Mulheres, p. 29.

${ }^{23}$ Chantal Mouffe também fez uso do "dilema Wollstonecraft" ao refletir acerca do feminismo e da democracia radical em prol de uma cidadania plural e agonística, a fim de denunciar que a Democracia representativa não compreende o sujeito plural. Quanto ao dilema afirma a filósofa: "exigir igualdade é aceitar a concepção patriarcal de cidadania, a qual implica que as mulheres devem parecer-se aos homens" (MOUFFE, El Retorno de lo Politico: Comunidade, cidadania, pluralismo, democracia radical, p. 115).

${ }^{24}$ Tradução nossa. "Pero apenas ha empezado a reconecer el problema del emplazamiento de mujer en un orden politico en cual la ciudadania fue creada a imagen y semejanza del hombre" (PATEMAN, El desorden de las mujeres: democracia, feminismo y teoria política, p. 31).

25 Tradução nossa. "Aunque la mujer haya exigido durante dos siglos que sus tareas y cualidades distintivas fueran parte de la ciudadania de mujer las que la posicionam en un lugar opuesto a la ciudadania o, en le mejor de los casos, en una relación contradictoria y paradójica con ésta. se espera que la mujer vista la piel del leon con melena y todo o bien se espera que tome su lugar entre los nuevos hombres postulados en la teoria democratica radical y que no se distinga de ellos" (PATEMAN, El desorden de las mujeres: democracia, feminismo y teoria politica, p. 31).

${ }^{26}$ PATEMAN, El desorden de las mujeres: democracia, feminismo y teoria politica.
} 
criadoras deles, uma vez que para estas, toda e qualquer ação ou fala era invisível. À vista disto, dar-lhes visibilidade em sua existência é fazer ver os litígios que se desenvolvem no seio do direito político social.

Nesta monta de invisibilidade, as representações formais eram de sistemas préestabelecidos nos quais o "outro" era pressuposto num determinado lugar vazio de fala, de cena e de pertença política. Neste esquema, reivindicações, soluções e direitos eram verticalizados, e manter-se na busca destes mesmos direitos era ainda desconhecer as diferenças deixadas do lado de fora das relações políticas. Foi, portanto, tal imitação que fez com que feministas como Pateman, reconduzissem as questões de Wollstonecraft, denominando-as de "o dilema". Assim, observamos que as controvérsias da emancipação eram comuns no próprio pensamento que circundava o ideário dos direitos da mulher, e a igualdade teria seu substrato no referencial masculino, que não considera as diferenças além de seus usufrutos de direitos próprios. Em suma, esse exemplo nos auxilia a compreender parte da hesitação de Nietzsche quanto à emancipação, ou seja, Nietzsche não é contra a emancipação da mulher, mas, sim, contrário às categorias que ela traz em sua essência, uma vez que emancipar-se só é possível à mulher fazendo uso de categorias políticas patriarcais, impregnadas de um tipo único de moral, platônico cristã, que as classifica.

Neste percurso de imitação da moral cristã patriarcal, passamos também a compreender por que tudo que se referia à mulher fora considerado, no âmbito desta tradição, sujo, impuro, imperfeito. A necessidade era que a mulher fosse refeita, limpa de sua impureza e rearranjada na ordem masculina. Nesta trajetória, o que é próprio da vivência da mulher deveria, segundo essa mesma tradição, ser deixado de fora, quando não, deveria mesmo ser extirpado, corrigido, como aponta Giacóia: “era necessário [...] colonizar e masculinizar o eterno feminino" 27 . E fixar a mulher num conceito é continuar a manutenção da aversão de tudo que é feminino, afinal, o conceito é a "razão mais visível pela qual cremos neste isolamento de grupos de ações; com eles não apenas designamos as coisas, mas acreditamos originalmente apreender-lhes a essência através deles" ${ }^{28}$. Observamos que se a ideia "mulher em si" advém de um ideal valorativo de uma moral platônico-cristã, o que se tem à mão, no processo de identificação, é fruto do idealismo e da inversão de valores em uma única moral que passou a nortear a própria formação dos indivíduos. À vista disso, o que seria ruptura (emancipação) acabou por manter a mesma rejeição e recusa sofrida pelas mulheres ao longo da história, a saber, a negação de fazer "aparecer" e o silenciamento daquilo que se pode dizer de si mesma. Propor, com base no ideário das virtudes modernas da ilustração, coroado com a Revolução Francesa, direitos iguais por sermos iguais, significou duas coisas, a saber, subtrair a própria diferença da qual a vida é constituída e negar o enfrentamento da própria condição da mulher na sociedade política.

Nesta perspectiva, a doutrina da igualdade emancipatória é um risco, pois a ideia de direitos iguais é, segundo Nietzsche, um deixar-se conduzir por uma concepção exclusivista do que é igual, assim como, desconsiderar a natureza sem sua tensão vital, distorcendo e renegando as pulsões (Trieben) e os afetos (Affekte) no processo de criação. Consequentemente, 'direitos', 'educação' e 'deveres iguais' são um sintoma do quão raso podem se tornar os impulsos que constituem a vida. Isto porque a igualdade é um tipo de

27 GIACÓIA, "Nietzsche e o feminismo", p. 15.

${ }^{28}$ NIETZSCHE, Humano demasiado humano II, MA/HH II, AS, §11, p. 170. 
construção que necessita de crença na razão, instituindo valores que são estranhos ao próprio mecanismo da vida. Nietzsche, ao tratar desse tema, circunda-se da necessidade de investigar a 'teleologia' atribuída à vida, ao mundo e à natureza pela metafísica, avesso à ideia da igualdade que funcionaria como uma inibidora da singularidade humana. Pensar as prerrogativas das ideias modernas é, portanto, atacar o cerne da metafísica que torna a mulher uma "abstração, que subtrai do feminino o seu elemento vital, insondável, não fixável - é isso o que Nietzsche critica" 29 .

A tentativa é refletir sobre a perda e o apagamento da natureza, da acontecência das perspectivas dos afetos, do cuidado de si que talvez ainda se mantenham próprios na mulher, a despeito do que ocorreu com o velho homem moderno cristão. Referimo-nos ao cuidado de si como um destaque de um tipo de fisiologismo elogioso de criação encarnada e vivenciada no próprio corpo, ou seja, do que está em constante criação de si $^{30}$, não com a finalidade de enquadrar a mulher num determinismo naturalista ou afetivo, mas antes, como tentativa de sinalizar sobre o perigo de um discurso que passa a se delinear em torno de uma verdade metafísica assentida pela própria mulher. A verdade de um tipo de ciência e do racionalismo que só empobrecem a vida como vontade que diz sim ao vir-a-ser. Assim, como afirma Nietzsche, "o que na mulher inspira respeito e com frequência temor é sua natureza, que é "mais natural que a do homem"'31. Naturalizar, portanto, é aqui considerar os impulsos e afetos que estão na vivência das ações humanas e, assim, manter-se de carne e osso na individualidade que se ganha.

Foi diante desta natureza que, segundo Nietzsche, o homem sempre se comportou com temor e compaixão. No entanto, na perda deste modo trágico e antagônico de existir, o desencantamento da mulher pôs-se em marcha. Porém, sucumbimos mesmo a este animal de chifres chamado de ideia moderna? Para esta resposta cabe agora dar voz ao que foi negado, forjado pela própria universalidade conceitual que finge a vida, e mantermo-nos nas nuances da suspeita e do deslocamento sobre o que ainda se tenta categorizar na mulher.

\section{Considerações Finais}

Este artigo intentou esclarecer a concepção de emancipação da mulher e o modo como este se liga à ideia de "mulher em si", uma vez que é através desta que poderíamos pensar acerca da igualdade e do feminismo iluminista de Mary Wollstonecraft, sob a análise de Carole Pateman, à luz do denominado "dilema Wollstonecraft". Ao trabalhar a emancipação como aspiração à igualdade, objetivamos demonstrar que a abordagem da igualdade em Nietzsche passa pelo trato da vida, aspectos fisiológicos no que respeitam aos impulsos, afecções e sentidos do corpo, como vontade, cuja incomensurabilidade de feitos resulta em determinadas formas de vida e nas ações sociais. Do proposto, verificamos ainda o quão difícil é tratar a questão da mulher em Nietzsche, não só por sua variação de sentido, mas por se tratar de uma oposição aos valores da filosofia metafísica, portanto, de uma filosofia de tradição dogmática.

\footnotetext{
${ }^{29}$ GIACÓIA, "Nietzsche e o feminismo", p. 17.

${ }^{30}$ NIETZSCHE, Ecce Homo, EH, §9, p. 45.

${ }^{31}$ NIETZSCHE, Para além de bem e mal, JGB/BM, \$239, p. 145.
} 
Vale ainda destacar que o tipo de ideia de "mulher em si" a que Nietzsche se opõe nada tem a ver com a mulher de carne e osso, mas trata-se de dizer de uma filosofia que aspira à verdade da ciência, fruto de uma educação aristocrática decadente e que, por vezes, encarna a verdade metafísica nunca alcançada pelos "filósofos inábeis, de terrível seriedade e desajeitada insistência que são na arte da sedução" 32 . Sendo assim, a tipologia é uma recusa da essencialização da mulher, essencialização de caráter dogmático dos conceitos universais e atemporais da própria filosofia, ação também exemplificada pelo chamado "dilema Wollstonecraft" de Pateman.

Desta forma, acreditamos que a contribuição deste artigo seja a de demonstrar que toda essencialização, ou seja, identidade atribuída à mulher, se não for uma farsa, é, no mínimo, uma adesão ao pensamento metafísico que sufoca as diferenças porque enfraquece a vivência singular de cada indivíduo. Neste sentido, podemos afirmar que Nietzsche antecipou os questionamentos que viriam posteriormente à terceira onda do feminismo, a saber, a implicação de se determinar um gênero para o decadente modo de representação política moldurada ainda nos moldes das ideias modernas.

\section{Referências bibliográficas}

FREZZATTI. Jr. "A superação da dualidade cultura/biologia na filosofia de Nietzsche”. In: Tempo da ciência, v. 11, n. 22, pp. $115-135,2004$.

GIACÓIA, O. "Nietzsche e o feminismo”. In: Natureza Humana, v. 4, n. 1, pp. 9 - 31, 2002.

LOPES, Rogério. "Entre ensaio e aforismo: notas sobre o modo de apresentação dos argumentos na filosofia de Nietzsche". In: FEITOSA, C.; BARRENECHEA, M.A. de; PINHEIRO, P. (Orgs.). A fidelidade à terra: arte, natureza e política. Assim falou Nietzsche IV. Rio de Janeiro: DP\&A, 2003. pp. 277-286.

MARESCA, J. “A emancipação da mulher”. Tradução Vânia Dutra de Azevedo. Cadernos Nietssche, 11, 2001. pp. 107-112.

MARTON, S. "Nietzsche e a crítica da democracia". Dissertatio, v. 33, pp. 17-33, 2011.

MOUFFE, Chantal. El Retorno de lo Político: Comunidade, ciudadania, pluralismo, democracia radical. Barcelona: Paidós, 1999.

NIETZSCHE, F. Para além de bem e mal. Trad. Paulo César de Souza. São Paulo: Companhia das Letras, 1992.

Ecce Homo. Como alguém se torna o que é. Trad. Paulo César de Souza. São Paulo: Companhia das Letras, 2008.

Humano, Demasiado Humano. Um livro para espiritos livres. Trad. de Paulo César de Souza. São Paulo: Companhia das Letras, 2000.

32 NIETZSCHE, Para além de bem e mal, p. 7. 
. A Gaia Ciência. Trad. Paulo César de Souza. São Paulo: Companhia das Letras, 2001. Humano demasiado humano II. Trad. Paulo César de Souza. São Paulo: Companhia das Letras, 2008.

2009 .

Genealogia da moral. Trad. Paulo César de Souza. São Paulo: Companhia das Letras,

PATEMAN, Carole. El desorden de las mujeres: democracia, feminismo y teoria politica. Trad. Luisa Fernanda Lassaque. Buenos Aires: Prometeo Libros, 2018.

WOLLSTONECRAFT, Mary. Reivindicação dos Direitos das Mulheres. São Paulo: Boitempo, 2016. 